\title{
A Study about Escitalopram Versus Citalopram in the Treatment of Depressive Disorders
}

Jasim M. Shindi *

Ali Talib Gallib**

\begin{abstract}
Background and aim: To compare the therapeutic efficacy, time onset of action, and patient compliance of escitalopram versus citalopram in the treatment of depressive disorders (DD) in Kirkuk City_Iraq

Materials and Method: 100 outpatients complaining of (DD) consulting psychiatric unit in Azadi teaching hospital were randomly categorized in to two therapeutic groups with escitalopram and citalopram. A structural interview form (questionnaire) containing socio demographic data and assessing 8 target symptom of depression according to (DSM-IV) derived from a preliminary pilot study in the same unit to reveal most common presentations of (DD) in Azadi teaching hospital, psychiatric unit inpatients in Kirkuk city, these symptoms were assessed according to a 4 degree scale (0_3 ) according to clinical interview by consultant psychiatrist on call, patients were followed up for 12 weeks.
\end{abstract}

Results: The majority of the study sample were aged group was between (30-39) years, the male formed $(38-40 \%)$, while the female $(60-62 \%)$ in each group, $(54-58 \%)$ of them were married, $(48 \%)$ of the escitalopram group had moderate economic level while $(44 \%)$ the of the citalopram group had low economic level, Muslim religion constitute (100\%), and the no history of medical illness formed (80$88 \%)$.

Conclusion: The our study concluded statistically significant superiority of escitalopram versus citalopram regarding the effectiveness, early symptom relief, patient compliance and significant change in dose score, After 12 weeks of treatment with fixed dose of $20 \mathrm{mg}$ of escitalopram and $20 \_40 \mathrm{mg}$.

Recommendations: Further comparative studies between escitalopram andcitalopram are recommended with large sample sizes and longer duration of follow up to cover all stages of treatment of depressive disorder (DD) symptom.

Keywords: Escitalopram, citalopram, depressive disorders (DD), efficacy.

\section{INTRODUCTION}

Depressive Disorders (DD) is a common and serious psychiatric condition with significant public health implication, all over the world which estimates reaching as high as 21 percent in incidence (FDA center for Drug Evaluation and Research, 2004; FDA center for Drug Evaluation and Research, 2009; Kaplan and Sadock, 1985).

The world health organization estimates that by 2030 (DD) will be second only to ischemic heart disease as an overall cause of disability and disease burden (Mathers and Loncar, 2006).

Selective serotonin reuptake inhibitors (SSRIs) inhibit serotonin reuptake leading to normalize the level of serotonin in the brain with no absolute effect on norepinephrine, muscarinic, histaminic, or alpha-adrenergic receptors, disturbance in the serotonin systems of the brain are key factors in development of (DD) (Bertam, 2011; British National Forulary, 2004).

SSRIS now considered as first line treatment for depression SSRIS efficacy is superior to placebo and other classes of antidepressants in treatment of (DD). Escitalopram is the pure actives S-Isomer (enantiomer) of the race mate $S_{\text {_ }}$ citalopram, citalopram composed of two mirror_image molecules, the stereoisomer $\mathrm{R}_{\text {- citalopram }}$ 50\% and S_citalopram 50\% (Bertam, 2011; British National Forulary, 2004; Kirino, 2012; Valery et. al., 2017).

Separation of and experimentation with the two enantiomers have found that the SSRIS activity of S_citalopram is 100 fold more potent than that of R_citalopram and has shown significant activities at the other monoamine transporters in more than 144 
binding sites (Valery et. al., 2017).

The single and multiple dose pharmacokinetics of both escitalopram and citalopram are linear and dose proportional in a dose range of 10_30 mg/day and 10_60 $\mathrm{mg} /$ day respectively.

Biotransformation for both is mainly hepatic with mean terminal half-life of about 27_32 hours and 35 hours respectively. Following a single oral dose $(20 \mathrm{mg})$ for escitalopram or up to $40 \mathrm{mg}$ tablet of citalopram the peak blood level occur at about 5 hours, 4 hours respectively.

The systemic clearance of both drugs are $600 \mathrm{ml} /$ minutes with approximately $7 \%$ of that due to renal clearance for escitalopram and $330 \mathrm{ml} /$ minutes with approximately $20 \%$ of that due to renal clearance (Bertam, 2011; Kasper, 2005). Side effects include insomnia, constricted pupils, dry mouth, dizziness, sweating, constipation, fatigue and indigestion (British National Forulary, 2011; Mathers, 2006). Delay ejaculation, anorgasmia ECG measurement should be considered for patients with cardiac diseases. electrolytes disturbance should be corrected before starting treatment (Van, 2009; MHRA drug safety update, 2011). These drugs should be used with caution in patients with epilepsy, or on electroconvulsive therapy, with uncontrolled diabetes hepatic dysfunction, susceptibility to angle closure glaucoma, history of mania, or in patients with bleeding disorders (Bertam et. al., 2011; MHRA drug safety update, 2011, FDA center for Drug Evaluation and Research, 2009). alcohol intake should be avoided, interaction with mono amine oxidize inhibiters can be fatal.

Over doses cause relatively minor untoward effects such as agitation tachycardia, hypertonia. The dose should be tapered over at least few weeks (Bertam et. al., 2011; Kirino, 2012) ${ }^{(1,8)}$. There is a minor risk of congenital heart defect when taken during early pregnancy. If these drugs used during third trimester there is a risk of neonatal withdrawal symptoms and persistent pulmonary hypertension in the neonate.

\section{RESULTS}

Table (1): Distribution of the study sample according to the demographical characteristics with mean and standard deviation

\begin{tabular}{||c|c|c|c|c|}
\hline \hline \multirow{2}{*}{ Characteristics } & Escitalopram (N=50) & Citalopram (N=50) & \multirow{2}{*}{ P. value } \\
\cline { 2 - 4 } Age & $20-29$ & 5 & 8 & \multirow{3}{*}{$\mathbf{0 . 6 6 0}$} \\
\cline { 2 - 5 } & $30-39$ & 23 & 25 & 12 \\
\hline
\end{tabular}

\section{MATERIALS AND METHODS}

A random single blind comparative therapeutic study was conducted between escitalopram and citalopram on an oral dose of $20 \mathrm{mg}$ as starting dose with follow up to 12 weeks on four occasions (base line, week 3, week 6, week 12). 100 outpatients complaining of (DD) consulting psychiatric unit in Azadi teaching hospital were divided randomly in to two treatment groups (50 patients for each) for the period from November 2013 to May 2014.

All the patients were informed about the details of the study and signed to share in the study according to the contract. Escitalopram and citalopram were prescribed freely in the hospital for each group and were asked to come for next follow up for assessing improvement of (DD) symptoms, compliance to drugs, and satisfaction in sharing in the study.

A structural interview form questionnaire containing survey for socio demographic data and a four degree scale from (0 to 3) for assessment of 8_target symptoms of depression derived from DSM_1V as regard response to treatment policy, the 8 target symptoms were chosen according to previous study in the same unit revealed most common presenting symptoms of depression among out patients consulting this unit the severity scale composed of four grades $(0=$ not at all, $1=$ some times, mild forms, $2=$ nearly always, moderate forms, $3=$ always sever forms).

After 12 weeks of treatment with fixed dose of escitalopram (20 mg) and a dose of (20 to $40 \mathrm{mg}$ ) of citalopram.

The total score of (DD) symptoms that reached (0 degree) were assessed as well as early symptom relief, patient compliance significant change in dosing scores using statistical package for the social science (SPSS ) version 19.0 was used, while differences in parameters between groups were evaluated with students $\mathrm{T}$. test. 


\begin{tabular}{|c|c|c|c|c|}
\hline & 50 andabove & 3 & 5 & \\
\hline \multicolumn{2}{|c|}{ Total } & 50 & 50 & \\
\hline \multicolumn{5}{|c|}{ Mean \pm SD $=2.63 \pm 1.447$} \\
\hline \multirow{2}{*}{$\begin{array}{c}\text { Gender } \\
\text { N }(\%)\end{array}$} & Male & $37(40.0)$ & $19(38.0)$ & 0.8728 \\
\hline & Female & $20(60.0)$ & $31(62.0)$ & 0.8981 \\
\hline \multicolumn{2}{|c|}{ Total } & 50 & 50 & \\
\hline \multirow{4}{*}{$\begin{array}{c}\text { Marital Status } \\
\quad \text { N (\%) }\end{array}$} & Single & $15(30.0)$ & $14(28.0)$ & 0.8527 \\
\hline & Married & $29(58.0)$ & $27(54.0)$ & 0.7893 \\
\hline & Divorced & $3(6.0)$ & $4(8.0)$ & 0.7055 \\
\hline & Widow & $3(6.0)$ & $5(10.0)$ & 0.4795 \\
\hline \multicolumn{2}{|c|}{ Total } & 50 & 50 & \\
\hline \multirow{3}{*}{$\begin{array}{c}\text { Financial Status } \\
\mathbf{N}(\%)\end{array}$} & Good & $12(24.0)$ & $8(16.0)$ & 0.3711 \\
\hline & Moderate & $24(48.0)$ & $20(40.0)$ & 0.5465 \\
\hline & Low & $14(28.0)$ & $22(44.0)$ & 0.1824 \\
\hline \multicolumn{2}{|c|}{ Total } & 50 & 50 & \\
\hline \multirow{2}{*}{$\begin{array}{l}\text { Religion } \\
\text { N (\%) }\end{array}$} & Muslim & $50(100.0)$ & $50(100.0)$ & - \\
\hline & Others & $0(0.0)$ & $0(0.0)$ & - \\
\hline \multicolumn{2}{|c|}{ Total } & 50 & 50 & \\
\hline \multirow{4}{*}{$\begin{array}{l}\text { History of other } \\
\text { illness } \\
\text { N (\%) }\end{array}$} & Non & $44(88.0)$ & $40(80.0)$ & 0.6625 \\
\hline & Hypertension & $4(8.0)$ & $9(18.0)$ & 0.1655 \\
\hline & Diabetes mellitus & $1(2.0)$ & $0(0.0)$ & 0.3173 \\
\hline & Others & $1(2.0)$ & $1(2.0)$ & - \\
\hline \multicolumn{2}{|c|}{ Total } & $\mathbf{5 0}$ & $\mathbf{5 0}$ & \\
\hline
\end{tabular}

Table (2): Distribution of the study sample according to the number of cases (n) and percentage for each escitalopram and citalopram of the whole study samples:

\begin{tabular}{|c|c|c|c|c|c|c||}
\hline \multirow{2}{*}{ Drug used } & \multirow{2}{*}{ Scores } & \multicolumn{4}{|c|}{ Time point N (\%) } & \multirow{2}{*}{ Total } \\
\cline { 3 - 7 } & & Baseline & Week 3 & Week 6 & Week 12 & \\
\hline \multirow{3}{*}{ Escitalopram } & Non & $70(10.8)$ & $100(15.5)$ & $179(27.7)$ & $297(46)$ & 646 \\
\cline { 2 - 7 } & Mild & $117(19.9)$ & $183(31.1)$ & $190(32.3)$ & $98(16.7)$ & 588 \\
\cline { 2 - 7 } & Moderate & $157(52.3)$ & $107(35.7)$ & $31(10.3)$ & $5(1.7)$ & 300 \\
\cline { 2 - 7 } & Sever & $56(84.8)$ & $10(15.2)$ & $0(0.0)$ & $0(0.0)$ & 66 \\
\hline \multirow{3}{*}{ Citalopram } & Non & $71(10.9)$ & $113(17.4)$ & $171(26.3)$ & $296(45.5)$ & 651 \\
\cline { 2 - 7 } & Mild & $116(21.2)$ & $154(28.2)$ & $180(33.0)$ & $96(17.6)$ & 546 \\
\cline { 2 - 7 } & Moderate & $168(48.8)$ & $119(34.3)$ & $49(14.2)$ & $8(2.3)$ & 344 \\
\cline { 2 - 6 } & Sever & $45(76.3)$ & $14(23.7)$ & $0(0.0)$ & $0(0.0)$ & 59 \\
\hline
\end{tabular}

Table (3): Distribution of the study sample according to the 8 items (indication) of total score, mean andstandard deviation score, and score changes during 12 weeks of treatment with escitalopram andcitalopram of the whole study samples:

\begin{tabular}{|c|l|c|c|c|r|}
\hline \multirow{2}{*}{ Items } & Time point & $\begin{array}{c}\text { Escitalopram } \\
(\mathbf{N = 5 0 )}\end{array}$ & $\begin{array}{c}\text { Citalopram } \\
(\mathbf{N = 5 0 )}\end{array}$ & t. & P. value \\
\hline \multirow{3}{*}{$\begin{array}{c}\text { Total scores, Mean } \\
\text { (SD) }\end{array}$} & Baseline & $12 .(4.4)$ & $11.7(2.6)$ & 0.330 & 0.742 \\
\cline { 2 - 6 } & Week 3 & $8.5(3.1)$ & $8.7(2.6)$ & -0.244 & 0.808 \\
\cline { 2 - 6 } & Week 6 & $5.0(3.0)$ & $5.6(2.6)$ & -0.926 & 0.357 \\
\cline { 2 - 6 } & Week 12 & $2.2(1.9)$ & $2.2(1.7)$ & -0.244 & 0.824 \\
\hline
\end{tabular}

Table (4): Distribution of the study sample according to the mean andstandard deviation (SD) of administered dose during 12 weeks of treatment with Escitalopram andCitalopram group.

\begin{tabular}{||c|l|c|c|c|c|}
\hline \hline Parameters & Time Point & $\begin{array}{c}\text { Escitalopram } \\
(\mathbf{N = 5 0 )}\end{array}$ & $\begin{array}{c}\text { Citalopram } \\
(\mathbf{N = 5 0 )}\end{array}$ & t. & P. value \\
\hline \multirow{2}{*}{$\begin{array}{c}\text { Administered dose, } \\
\text { mean(SD) }\end{array}$} & Baseline & $18.8(3.3)$ & $19.6(2.0)$ & -1.476 & 0.143 \\
\cline { 2 - 6 } & Week 3 & $19.2(2.7)$ & $19.8(1.4)$ & -1.376 & 0.172 \\
\cline { 2 - 6 } & Week 6 & $22.6(5.6)$ & $25.2(8.6)$ & -1.783 & 0.078 \\
\hline
\end{tabular}




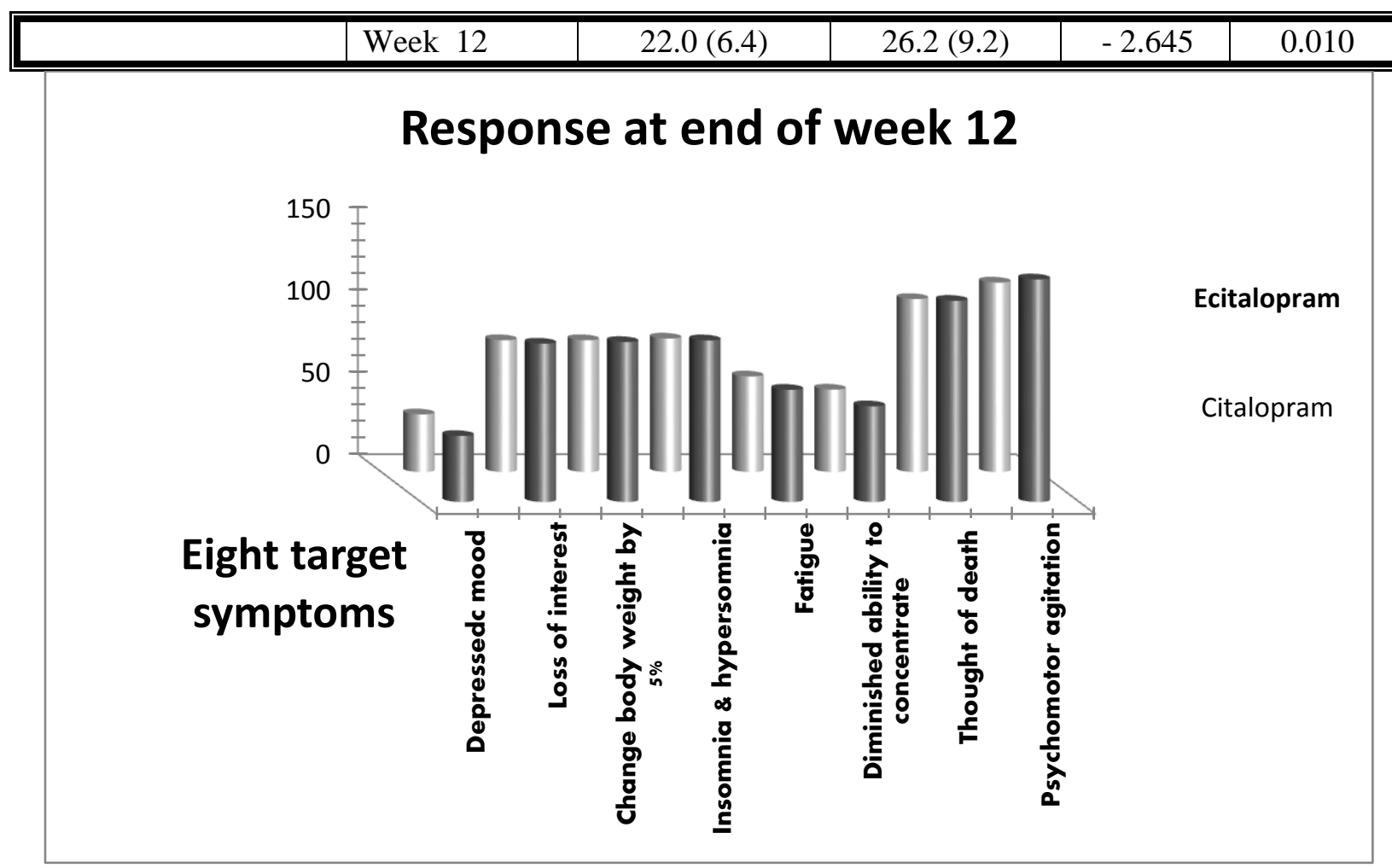

Figure (1) Distribution of score of response the citalopram andescitalopram according to the eight target symptoms in the whole study sample.

This figure shows that the highest response score of escitalopram were in thought of death andpsychomotor agitation target symptoms.

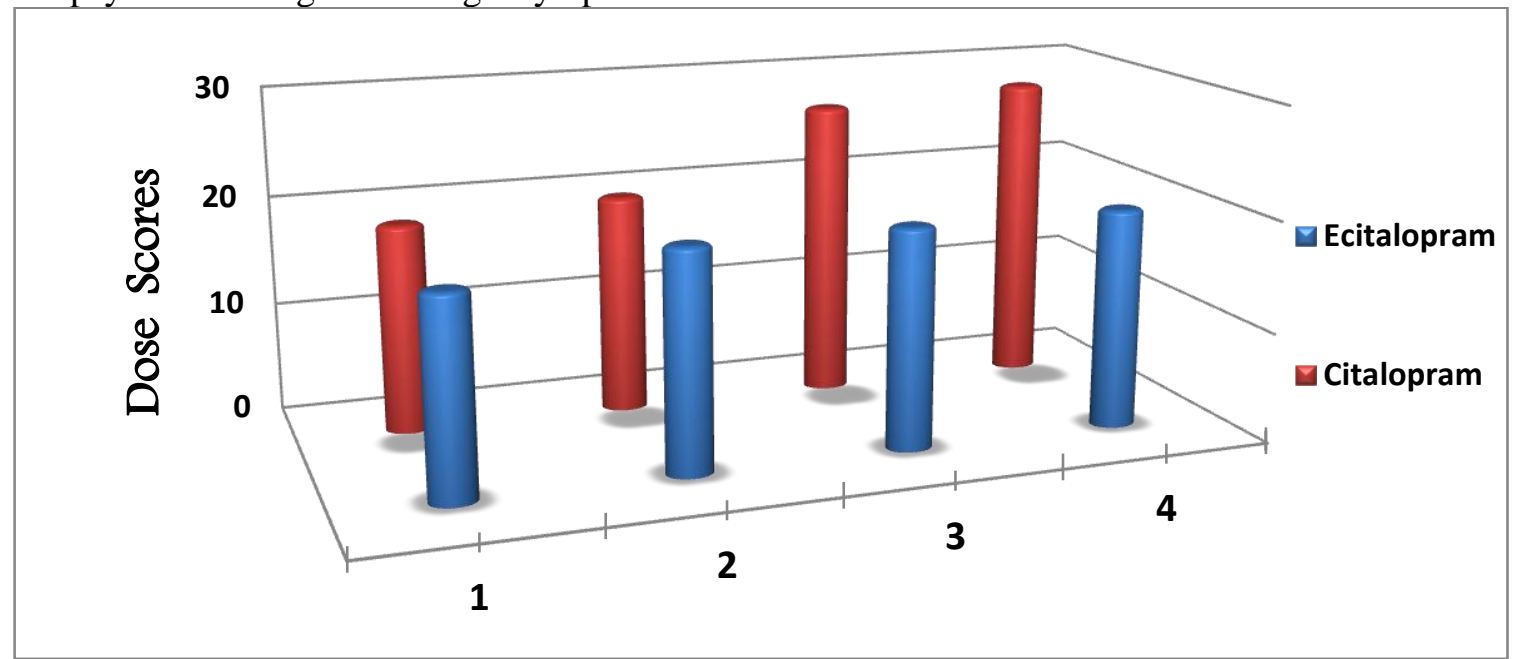

Figure (2): Distribution the dose scores in both citalopram andescitalopram drug according to the duration of treatment in the whole study sample.

This figure shows that the escitalopram drug group had fixed dose $20 \mathrm{mg} / \mathrm{day}$, while the citalopram drug group needed increasing up to $40 \mathrm{mg} /$ day to get the best possible result at the end 12 weeks of treatment.

\section{DISCUSSION}

Mean and standard deviation (SD), number of cases (No.) and percentage (\%) for patients characteristics of each escitalopram and citalopram groups are described in table (1) referring to good matching of selected patients in the groups. Although mean and
(SD) of the results of 12 weeks treatment yelled non-significant difference (table 4) all treated individual symptom of (DD) at the end of 12 week showed high response to escitalopram than those treated with citalopram (figure 1). The superiority of escitalopram over citalopram was more 
pronounced in severely depressed patients due to high degree of selectivity of $\mathrm{S}$. isomer of the drug and good patients compliance for S. isomer, this results are congruent with many studies in the world about efficacy comparison between these two drugs (Gorman et. al., 2008; Kirino, 2012; UIIa et. al., 2004; Valery et. al., 2007).

From week 6 andup words 21 patients out of 50 patients in citalopram group needed higher doses according to assessments done by consultant psychiatrists on call from $20 \mathrm{mg}$ up to $30 \_40 \mathrm{mg}$ to get the same response as that with $20 \mathrm{mg}$ of escitalopram (figure 2) the significant changes in dose score (P. value 0.001) shown in (table 5) indicated that escitalopram is superior to citalopram as regards to treatment of (DD) this result is corresponding with other studies in the world (Burke et. al., 2002; UIIa et. al., 2004).

\section{CONCLUSIONS}

The results of the current study confirmed that the SSRI escitalopram $20 \mathrm{mg}$ tablet had better efficacy than citalopram 20 $\mathrm{mg}$ tablet as regards magnitude of effect, cost andtime onset of action.

\section{RECOMMENDATION}

Further comparative studies between escitalopram andcitalopram are recommended with large sample sizes and longer duration of follow up to cover all stages of treatment of depressive disorder (DD) symptom.

\section{REFERRENCES}

Bertam, G.; katzung, MD.; Susan, B. Anthony J. trevor. (2011). Basic andclinical pharmacology 12 Edition.

British National Forulary 62. (2011). Chapter 4. Central nervous system. P.p. 235-248.

Burke, WJ.; Gergel, I.; Bose, A. (2002). Fixed-dose trial of the single isomer SSRI,escitalopram in depressed outpatients. Journal of clinical psychiatry.

FDA center for Drug Evaluation and Research. (2009). Review and evaluation of clinical data for application. 21-323.

Gorman, J.; Korotzer, A.; Su, G.; (2002). Efficacy comparison of escitalopram and citalopram in the treatment of major depressive disorder: pooled analysis of placebo_ controlled trials. CNS. 7:40_44.
Kaplan and Sadock. (1985). A comprehensive textbook of psychiatry Lippincott Williams Wilkins. (5 $5^{\text {th }}$ Edition).

Kasper, S.; Stein, DJ.; Loft, H.; Nil, R. (2005). Escitalopram in the treatment of social anxiety disorder: Randomized, placebo_ controlled, flexible _dosage study. The British Journal of psychiatry :the journal of mental science. 186 (3). 2226.

Kirino, E. (2012). Escitalopram for the management of major depressive disorder : a review of its efficacy ,safety, and patient acceptability. 6:853_61.doi:10.214 7 :PPA ,S22495.

Mathers, CD.; and Loncar, D. (2006). Projections of global mortality and burden of disease from 2002 to 2030 . PLos Med. 3 (11).

MHRA drug safety update. (2011). Citalopram and escitalopram: $Q T$ interval prolongation new maximum daily dose restrictions (including in elderly patients), contraindications, and warnings.

Patten; SB.; Kennedy, SH.; Lam R W. (2009). Canadian network for mood and anxiety Treatments (CANMAT) clinical Guidelines for the Management of Major Depressive Disorder in Adults. I Classification, burden and principles of management. $J$ Affect Disorder.117 SUPPI,1s5.14.

UIIa, Lepola; Alan,Wade.; and Henning, Friis Andersen. (2004). Do equivalent doses of escitalopram and citalopram have similar efficacy? Apooled analysis of two positive placebo_controlled studies in major depressive disorder. International Clinical psychopharma. 19:149_155.

Valery,Y.;Yevtushenko,A.; Belous, Yevgenia G.; Yevtushenko, Sergei E.; Gusinin, Oleg J.; Buzik, MD.; and Tatiana V. (2007). Efficacy and Tolerability of Escitalopram Versus Citalopram Major Depressive Disorder:A 6 _Week, Multicenter, Prospective, Randomized, Double-blind, Active _Controlled Study in Adult Outpatients .Clinical Therapeutics. Vol (29).

Van, Gorp F.; Whyte Im.; Isbister gk.(2009). clinical and ECG effects of escitalopram overdose Ann. Emerg Med.54:404_408. 